\title{
Modelling of heat transfer and hydrodynamic with two kinetics approaches during supercritical water oxidation process
}

\author{
S. Moussière ${ }^{\mathrm{a}, *}$, C. Joussot-Dubien ${ }^{\mathrm{a}}, \mathrm{P}$. Guichardon ${ }^{\mathrm{b}}$, O. Boutin $^{\mathrm{b}}$, \\ H.-A. Turc ${ }^{\mathrm{c}}$, A. Roubaud ${ }^{\mathrm{a}}$, B. Fournel ${ }^{\mathrm{a}}$ \\ ${ }^{a}$ CEA Pierrelatte, DEN/DTCD/SPDE/LFSM, BP111, 26702 Pierrelatte, France \\ ${ }^{\mathrm{b}}$ LPPE, UMR-CNRS 6181, BP 80, Europôle de l'Arbois, 13545 Aix en Provence, France \\ ${ }^{\mathrm{c}}$ CEA Marcoule, DEN/DRCP/SEAT/GEDM, BP17171, 30207 Bagnols/Ceze, France
}

\begin{abstract}
Supercritical water oxidation is an innovative and very efficient process to treat hazardous organic waste. In order to better understand the complex physic phenomena involved in this process, and to design more efficient reactors or to insure future efficient scale-up, a simulation with the Computational Fluid Dynamics software FLUENT was carried out for a simple tubular reactor.

The turbulent non-reactive flow is well-represented using the $k-\varepsilon$ model. Nevertheless, the $k-\omega$ model gives better results when a source term is added to take into account the chemical reaction.

Two approaches are used to model the reaction rate: an Arrhenius law and the Eddy Dissipation Concept (EDC) generally used to describe combustion reactions.

The results of this simulation using Arrhenius law, are in good agreement with experimental data although a simple thermohydraulic model was used. Moreover, the sensitiveness to the inlet temperature has been demonstrated. It influences the reaction start-up and the shape of the measured wall temperature peak. Equally, the simulated temperature profiles using Eddy Dissipation Concept model are in good agreement with experimental ones. Hence, the two approaches give similar results. Nevertheless, the EDC model predicts more precisely the thermal peak location at the reactor wall.
\end{abstract}

Keywords: Supercritical water oxidation; Heat transfer; Eddy Dissipation Concept (EDC); FLUENT; Computational Fluid Dynamics (CFD); $k-\omega$

\section{Introduction}

Supercritical water oxidation (SCWO) is a technology of high interest to treat organic liquid wastes. The supercritical water $(P>22.1 \mathrm{MPa}, T>647 \mathrm{~K})$ offers physicochemical properties between those of gas and liquid. Thereby, waste and oxygen are highly miscible in supercritical water leading to a single homogeneous phase and hence to the main advantage of no transfer limitation. The oxidation reaction is completed within seconds. The temperature is relatively low compared to classical combustion mode, so there is no formation of gaseous $\mathrm{SO}_{x}$ or $\mathrm{NO}_{x}$, which is an environmental asset.

\footnotetext{
* Corresponding author. Fax: +33 45504342 .

E-mail addresses: sandrine_moussiere@yahoo.fr (S. Moussière), bruno.fournel@cea.fr (B. Fournel)
}

The two well-known problems associated to the process are corrosion and salt precipitation. First, heteroatoms such as sulphur, chlorine or phosphorus lead to the production of the corresponding acids, respectively, $\mathrm{H}_{2} \mathrm{SO}_{4}, \mathrm{HCl}$ and $\mathrm{H}_{3} \mathrm{PO}_{4}$. Those acids can induce a corrosion attack of material especially under sub-critical temperatures [1]. Secondly, the salts contained in the waste or produced during the reaction can precipitate and lead to the plugging of the reactor. This precipitation is due to the low value of the dielectric constant and the ionic product of water in supercritical conditions [2-4].

Recently, the technology of double shell reactor has been emerging to overcome those problems. The external vessel withstands the pressure and the inner tube is made of corrosionresistant material. Salt precipitation is commonly reduced by means of a cool wall or a transpiring wall [5-7]. A new reactor concept has been patented and developed for nuclear waste. It includes a horizontal stirrer which keeps salt under suspension 


\begin{tabular}{|c|c|}
\hline \multicolumn{2}{|c|}{ Nomenclature } \\
\hline$C_{\mathrm{p}}$ & specific heat $(\mathrm{J} / \mathrm{kg} \mathrm{K})$ \\
\hline$d_{\mathrm{p}}$ & grain size $(\mathrm{m})$ \\
\hline$h$ & heat transfer coefficient $\left(\mathrm{W} / \mathrm{m}^{2} \mathrm{~K}\right)$ \\
\hline$\Delta H_{i}$ & species enthalpy $(\mathrm{kJ} / \mathrm{kg})$ \\
\hline$k$ & kinetic energy per unit mass $(\mathrm{J} / \mathrm{kg})$ \\
\hline$\dot{m}$ & $\begin{array}{l}\text { mass transfer between the fine structures and the } \\
\text { surrounding }\left(\mathrm{s}^{-1}\right)\end{array}$ \\
\hline$R_{j}$ & $\begin{array}{l}\text { volumetric rate of creation of species } j \text { (unit } \\
\text { depending on the reaction model) }\end{array}$ \\
\hline$S_{\mathrm{h}}$ & source term $\left(\mathrm{W} / \mathrm{m}^{3}\right)$ \\
\hline$T$ & temperature $(\mathrm{K})$ \\
\hline$u$ & velocity $(\mathrm{m} / \mathrm{s})$ \\
\hline \multicolumn{2}{|c|}{ Greek letters } \\
\hline$\chi$ & ratio of the reactive fine structures in EDC model \\
\hline$\varepsilon$ & $\begin{array}{l}\text { dissipation rate of turbulence kinetic energy } \\
\left(\mathrm{m}^{2} / \mathrm{s}^{3}\right)\end{array}$ \\
\hline$\varepsilon_{\mathrm{p}}$ & porosity \\
\hline$\gamma^{*}$ & $\begin{array}{l}\text { mass fraction occupied by the fine structures in } \\
\text { EDC model }\end{array}$ \\
\hline$\lambda$ & thermal conductivity $(\mathrm{W} / \mathrm{m} \mathrm{K})$ \\
\hline$\mu$ & dynamic viscosity (kg/m s) \\
\hline$v$ & kinematic viscosity $\left(\mathrm{m}^{2} / \mathrm{s}\right)$ \\
\hline$\rho$ & fluid density $\left(\mathrm{kg} / \mathrm{m}^{3}\right)$ \\
\hline$\tau^{*}$ & time scale (s) \\
\hline$v_{j}$ & $\begin{array}{l}\text { stoichiometric coefficient for reactives or prod- } \\
\text { ucts } j \text { in reaction } R\end{array}$ \\
\hline$\omega$ & specific dissipation rate $\left(\mathrm{s}^{-1}\right)$ \\
\hline \multicolumn{2}{|c|}{ Subscripts } \\
\hline 0 & reference \\
\hline f & fluid \\
\hline $\mathrm{s}$ & solid \\
\hline
\end{tabular}

to avoid the deposition and a titanium inner tube which limits the corrosion phenomena $[8,9]$.

To scale up this reactor, a better understanding of the whole phenomenon in the SCWO process is previously required. In the literature, many simulations using a one-dimensional approach have been carried out to study heat transfer and energy recovery in SCWO process $[6,10,11]$. In many previous works, the reactor is tubular and assimilated to a heat exchanger with an internal energy source. Other works show more detailed simulation in two and three dimensions. A three-dimensional simulation of continuously-fed stirred tank reactor has been carried out and demonstrates that CFD is a well-adapted tool to study and improve reactor efficiency [14]. Nevertheless, in this simulation, the waste mass flow rate is very small, equal to $1 \mathrm{~g} / \mathrm{h}$. Several reactors, a tubular one [12] and a vessel one [13] were simulated in two dimensions. In both cases, the turbulence flow is described with a $k-\varepsilon$ model. For vessel reactor, the experimental near wall temperatures are in good agreement with predicted temperatures in three places. For a quasi-adiabatic vertical reactor, Dutournié et al. [12] recommend a one-dimensional approach because there is no radial temperature and no concentration gradient due to a flat velocity profile. The simulated temperature profiles obtained are in good agreement with experimental data [10]. But, because of quasi-adiabatic reactor, temperature profiles at reactor wall are very similar in four tests. Moreover, no turbulence model was used.

The tubular reactor studied in this work is not adiabatic. A temperature peak can be observed at reactor wall during the oxidation of dodecane. Hence, the temperature gradient is supposed even more important inside the reactor. To compute the temperature field and the maximum temperature reached in the reactor, a CFD simulation of the tubular reactor is a well-suited method.

The simulation was performed with FLUENT $^{\circledR}$ 6.2.16. In this study, the ability of this commercial CFD code to describe all aspects of the complex thermohydraulic phenomena involved in the SCWO process, is checked.

The aim of this study is to get onto the hydrodynamic model within the framework of the flow of a supercritical fluid, and to investigate the influence on turbulence on reaction rate. Two approaches are used in order to simulate the oxidation reaction rate. Firstly, the reaction rate is simulated with an Arrhenius law. The influence of some parameters is investigated like inlet temperature and heat transfer coefficient between the wall of the reactor and the fluidized sand bath used for heating and controling temperature. Secondly, the reaction rate is simulated with the Eddy Dissipation Concept (EDC) model which takes into account for chemistry-turbulence interactions.

\section{Materials and methods}

\subsection{Experimental set up}

The tubular reactor is a tube made of SS316 of $2.5 \mathrm{~m}$ length and an i.d./o.d. of $9.525 / 5.2 \mathrm{~mm}$. The tube is plunged in a fluidized sand bath in order to keep a homogeneous temperature value about $773 \mathrm{~K}$. The flowsheet of this process is shown in Fig. 1 .

Oxidant (40\% oxygen and $60 \%$ nitrogen) is pressurized by a NOVA SWISS membrane compressor with a maximum pressure of $55 \mathrm{MPa}$ and a maximum flow rate of $3000 \mathrm{~N} \mathrm{~L} / \mathrm{h}$. Water is pressurized by a LEWA membrane pump. The pump allows a flow ranging between 500 and $4000 \mathrm{~g} / \mathrm{h}$. The waste is pressurized

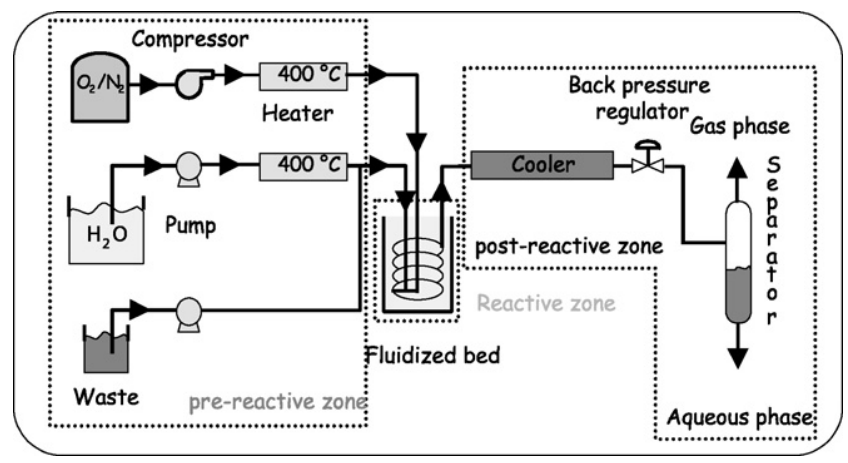

Fig. 1. Flow sheet of supercritical water oxidation process. 
by a LEWA pure membrane pump with a flow ranging from 100 to $400 \mathrm{~g} / \mathrm{h}$.

Oxidant and water are heated separately to $673 \mathrm{~K}$ by means of an electric heater. Water and waste are mixed before entering the reactor where the oxidation reaction takes place. At the outlet of the reactor, the effluents are cooled down and then depressurized through a back pressure regulator. Gas and liquid are then continuously separated and monitored.

The reactor is equipped with 20 thermocouples in order to measure the temperature profile along the outer reactor wall. The spacing between thermocouples is short from 0 to $1 \mathrm{~m}$ from the entrance and then enlarged. In the first part of the reactor, a peak of temperature appears, due to the strong exothermicity of the reaction. Depending on the operating conditions, the shape and the height of temperature peaks vary. Simulation is useful to provide more data on the temperature inside the reactor.

\subsection{Calculations}

The aim of this study is to check the ability of this commercial CFD code to model main aspects of the complex thermohydraulic phenomena involved in the SCWO process.

\subsubsection{Meshing}

The preliminary step is to represent the simplified 2D axisymetric geometry of the tubular reactor thanks to GAMBIT $^{\circledR}$ software. The tubular reactor mesh is shown in Fig. 2. The built mesh contains about 35,000 cells. Their distributions are refined in the zone where a large temperature variation is expected, in the first part of the reactor. To simulate the fluid zone, 20 nodes are shared out on a fluid section. They are closer in the vicinity of the wall.

\subsubsection{Model}

Considering the system as incompressible fluid is the major hypothesis needed, though a supercritical fluid is usually considered like a compressible fluid. Nevertheless, the fluid flow rate is lower by far than sound speed in the medium. The Mach number defined by the ratio of the fluid velocity over the sound speed is lower than 0.1 . So, the compressibility effects can be neglected and the variation of gas density with pressure can be ignored in the flow modelling.

The experimental runs were carried out at $30 \mathrm{MPa}$ in order to ensure supercritical conditions. So, all reactions and fluid evolutions are considered to be isobaric at $30 \mathrm{MPa}$. Fluids properties at $30 \mathrm{MPa}$ were specified in FLUENT ${ }^{\circledR}$. The standard enthalpies of each species are calculated at $30 \mathrm{MPa}$ using a thermo-chemical cycle. An ideal mixing is assumed and density, viscosity, thermal conductivity and specific heat of mixing are calculated by weighted means.

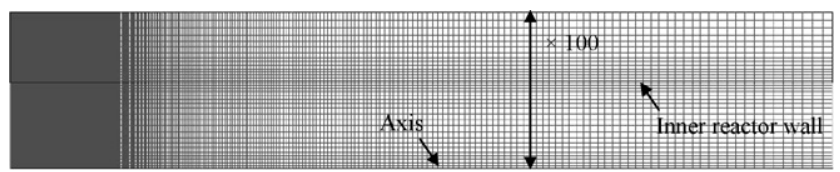

Fig. 2. Mesh of tubular reactor in 2D axisymetric.
FLUENT $^{\circledR}$ software solves the classical mass, momentum and energy conservation equations to describe the fluid behaviour and properties. In order to model a turbulent flow, models with only two equations, based on the computation of the turbulent viscosity, are commonly used. Two models have been tested, the $k-\varepsilon$ model developed by Jones and Launder [15] and the $k-\omega$ turbulence model developed by Wilcox [16].

In the $k-\varepsilon$ model, $\mu_{\mathrm{t}}$ is defined using $k$, the turbulence kinetic energy and $\varepsilon$, its dissipation rate as shown in Eq. (1). $k$ and $\varepsilon$ add two equations to the system.

$\mu_{\mathrm{t}}=\frac{0.0845 \rho k^{2}}{\varepsilon}$

In the $k-\omega$ turbulence model, $\mu_{\mathrm{t}}$ is defined using the turbulence kinetic energy $k$ and the specific dissipation rate $\omega$ as shown in Eq. (2). $k$ and $\omega$ solving add two equations to the system.

$\mu_{\mathrm{t}}=\frac{\rho k}{\omega}$

The quantity $\omega$ can be thought of as the ratio of $\varepsilon$ to $k$. Thereby, the $k-\omega$ model is more accurate than the $k-\varepsilon$ model for incompressible boundary layers in adverse pressure gradient. Moreover, the model equation can be integrated through the viscous sub-layers with no particular difficulty.

Chemistry is taken into account thanks to a source term named $S_{\mathrm{h}}$.

$S_{\mathrm{h}}=\sum_{j}\left(\Delta H_{j}^{0}\left(T_{0}\right)+\int_{T_{0}}^{T} v_{j} C_{\mathrm{p} j} \mathrm{~d} T\right) R_{j}$

\subsubsection{Simplified chemical kinetics}

The reaction considered in this simulation is the oxidation of dodecane. Dodecane is a classical model compound for the contaminated organic waste resulting of the retreatment of the spent nuclear fuel. The oxidation of dodecane has been studied by Limousin [17] at $30 \mathrm{MPa}$ pressure in the same tubular reactor. A two-step reaction mechanism with formation of acetic acid has been investigated.

$\mathrm{C}_{12} \mathrm{H}_{26}+6.5 \mathrm{O}_{2} \rightarrow 6 \mathrm{CH}_{3} \mathrm{COOH}+\mathrm{H}_{2} \mathrm{O}$

$\mathrm{CH}_{3} \mathrm{COOH}+\mathrm{O}_{2} \rightarrow \mathrm{CO}_{2}+\mathrm{H}_{2} \mathrm{O}$

For both reactions, the kinetic parameters have been determined from 160 tests at temperatures from 673 to $773 \mathrm{~K}$, water mass flow rates from 1000 to $3200 \mathrm{~g} / \mathrm{h}$ and dodecane mass flow rates from 8 to $32 \mathrm{~g} / \mathrm{h}$. The measurement of TOC in aqueous effluent and $\mathrm{CO}_{2}$ and $\mathrm{CO}$ in gaseous effluent at the outlet made it possible to check the mass balance. The pre-exponential constant, the activation energy and the order for each reaction have been obtained by minimization of the sum of the square of yield deviation. Both reactions parameters are presented in Table 1. In both cases, because oxygen is in large excess its reaction order is assumed to be equal to zero [19].

\subsubsection{Eddy Dissipation Concept}

In this model developed by Magnussen [18], reaction rates are supposed to be controlled by the turbulence motion. The 
Table 1

Kinetics parameters for dodecane oxidation

\begin{tabular}{|c|c|c|c|}
\hline & Pre-exponential constant $\left(\mathrm{s}^{-1} \mathrm{~mol}^{(1-\alpha)} \mathrm{L}^{(1-\alpha)}\right)$ & Activation energy $(\mathrm{kJ} / \mathrm{mol})$ & Reaction order \\
\hline Reaction 1 & $6 \times 10^{14}$ & 147 & 2.87 \\
\hline Reaction 2 & $1 \times 10^{7}$ & 98 & 1.33 \\
\hline
\end{tabular}

mean reaction rate is based on the following assumption: the chemical reaction takes place in the fine structures, that is to say the smaller eddy, where reactants are mixed at a molecular scale. The mass fraction occupied by fine structures is modelled as

$\gamma^{*}=C_{\gamma}\left(\frac{\nu \varepsilon}{k^{2}}\right)^{3 / 4}$

where the asterisk denotes fine structures quantities, $v$ is kinematic viscosity, and the constant $C_{\gamma}=2.1377$

Species are then assumed to react within the fine structures over a time scale $\tau^{*}$

$\tau^{*}=C_{\tau}\left(\frac{\nu}{\varepsilon}\right)^{1 / 2}$

where $C_{\tau}$ is a time scale constant equal to 0.4082 .

The mass transfer by unity of fluid and time, between the fine structures and the surrounding can be expressed as

$\dot{m}=\frac{C_{\tau}}{C_{\gamma}}\left(\frac{\nu \varepsilon}{k^{2}}\right)^{1 / 4} \frac{\varepsilon}{k}$

The reaction rate is defined as

$\tilde{r}_{i}=\dot{m} \frac{\chi}{1-\gamma^{*} \chi} \overline{C_{\min }}$

where $\chi$ is the fraction of fine structures which reacts and $\overline{C_{\min }}$ is the smallest of $\overline{C_{\mathrm{w}}}$ and $\overline{C_{\mathrm{O}_{2}}} / s$ where $\overline{C_{\mathrm{w}}}$ and $\overline{C_{\mathrm{O}_{2}}}$ are the local mean concentrations of waste and oxygen, and $s$ the stochiometric oxygen requirement.

\subsubsection{Heat transfer coefficient}

The heat transfer coefficient between the reactor wall and the fluidized sand bath mainly depends on sand grain size. It can be assessed with the Wender and Cooper correlation.

$$
\begin{aligned}
& \frac{h \times d_{\mathrm{s}}}{\lambda_{\mathrm{f}}\left(1-\varepsilon_{\mathrm{p}}\right)}\left(\frac{\lambda_{\mathrm{f}}}{C_{\mathrm{pf}} \times \rho_{\mathrm{f}}}\right)^{0.43} \\
& =3.5 \times 10^{-4}\left(\frac{u \times d_{\mathrm{p}} \times \rho_{\mathrm{f}}}{\mu}\right)^{0.23}\left(\frac{C_{\mathrm{ps}}}{C_{\mathrm{pf}}}\right)^{0.8}\left(\frac{\rho_{\mathrm{s}}}{\rho_{\mathrm{f}}}\right)^{0.66}
\end{aligned}
$$

In our case, the grain size is ranging from 50 to $100 \mu \mathrm{m}$. According to Eq. (8), the heat transfer coefficient is estimated between 340 and $580 \mathrm{~W} / \mathrm{m}^{2} \mathrm{~K}$.

The heat transfer coefficient between the fluid and the inner wall of the reactor is computed by FLUENT $^{\circledR}$ software using a standard wall function.

\subsubsection{Initial conditions}

The main input parameters are summarized in Table 2 with the set values for each of them. A uniform temperature variation of $20 \mathrm{~K}$ is assumed at the reactor wall. Indeed, the experimental
Table 2

Parameters and fixed values used in the simulation

Inlet temperature $(\mathrm{K})$

Wall temperature $(\mathrm{K})$

Wall temperature gradient $(\mathrm{K} / \mathrm{m})$

$h\left(\mathrm{~W} / \mathrm{m}^{2} \mathrm{~K}\right)$

data show a fluidized sand bath temperature of $793 \mathrm{~K}$ at the bottom and a temperature of $773 \mathrm{~K}$ at the top. This variation corresponds to the temperature gradient of $8 \mathrm{~K} / \mathrm{m}$ specified in Table 2.

\section{Results and discussions}

\subsection{Hydrodynamic model determination}

\subsubsection{Influence of the hydrodynamic model on the turbulent flow simulation}

In a first evaluation, the flow appears to be turbulent; Reynolds number at reactor entrance ranges from 3500 to 6000 . We have simulated a laminar flow, and a turbulent flow with two different models, in order to check this assumption. For the turbulent flow case, we use the $k-\varepsilon$ and the $k-\omega$ models in order to simulate the hydrodynamics in the reactor. It is known that the $k-\omega$ model offers a better description of the flow at the wall than the $k-\varepsilon$ model. The boundary conditions are the same as operating condition of test "blank" shown in Table 3.

If we assume the flow is laminar, the specific viscosity is equal to the dynamic viscosity. The result of the laminar flow simulation is shown in Fig. 3. We can observe that the calculation result is not in agreement with the experimental data. The wall temperature is equal to the fluidized sand bath temperature. A laminar

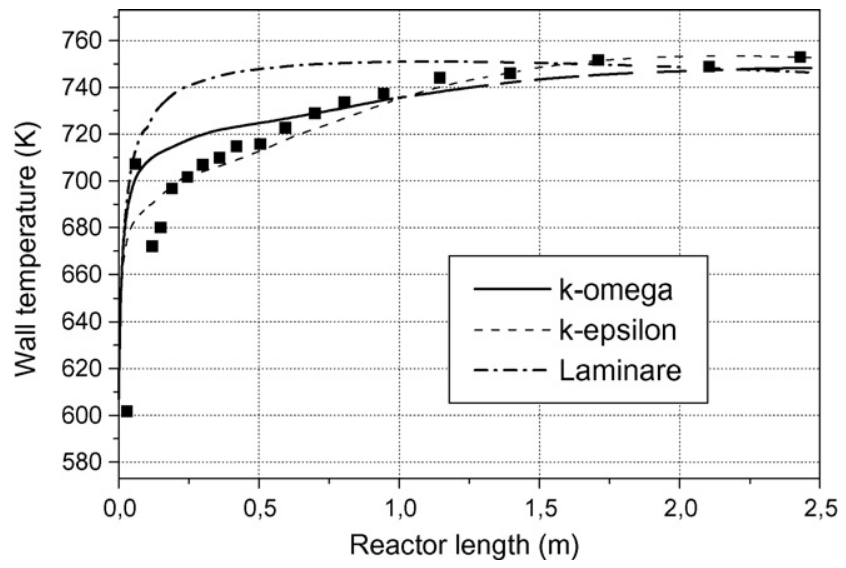

Fig. 3. Simulated wall temperature using a laminar flow assumption, a $k$-epsilon and a $k$-omega turbulent model for a non reactive flow. 
Table 3

Operating conditions for the three tests

\begin{tabular}{|c|c|c|c|c|c|}
\hline & Blank & Test 1 & Test 2 & Test 3 & Test 4 \\
\hline Mass flow rate $(\mathrm{kg} / \mathrm{s})$ & $8.797 \times 10^{-4}$ & $9.323 \times 10^{-4}$ & $8.936 \times 10^{-4}$ & $7.946 \times 10^{-4}$ & $8.661 \times 10^{-4}$ \\
\hline$\%_{\mathrm{wt}} \mathrm{O}_{2}$ & 14.99 & 14.87 & 16.29 & 12.87 & 12.78 \\
\hline$\%_{\mathrm{wt}} \mathrm{N}_{2}$ & 22.49 & 22.30 & 24.44 & 19.31 & 19.17 \\
\hline$\%_{\text {wt }}$ Dodecane & 0 & 2.652 & 3.124 & 3.216 & 3.198 \\
\hline
\end{tabular}

flow does not suitably represent the hydrodynamic inside the reactor. The heat transfers are experimentally enhanced due to the turbulent flow. The simulated wall temperatures obtained using a $k-\varepsilon$ model and a $k-\omega$ model, are shown in Fig. 3 . The simulated temperature profiles are similar to the experimental one observed. Nevertheless, the best results are obtained with the $k-\varepsilon$ model. Both models will be used in order to simulate the oxidation reaction to conclude on the accuracy of one model to one other.

\subsubsection{Influence of the hydrodynamic model on the reactive turbulent flow simulation}

This simulation is performed in the same condition as test 1 taking into account the oxidation reaction of dodecane using Arrhenius rate based on the two step chemistry mechanism. The simulated wall temperature profiles obtained when the hydrodynamic is defined by a $k-\varepsilon$ and by a $k-\omega$ models are shown in Fig. 4. Using a $k-\varepsilon$ model, we notice a temperature peak at the wall similar to the experimental one observed but the shape is different. The simulation assumes a more local oxidation reaction than experimentally. The best results are obtained with the $k-\omega$ model. The simulated wall temperature profiles using $k-\omega$ model shown in Fig. 4 is in good agreement with experimental data. For both turbulent models, the deviation for the simulated wall temperature in relation to the experimental data is minimal between 1 and $2.5 \mathrm{~m}$ that is to say when the oxidation reaction is completed. The $k-\omega$ model represents more suitably the hydrodynamic in the reactor than the $k-\varepsilon$ model. The maximum deviation is equal to $41 \mathrm{~K}$ for the $k-\omega$ model whereas it is equal to $104 \mathrm{~K}$ for the $k-\varepsilon$ model. This maximum deviation is noticed in the first part of the

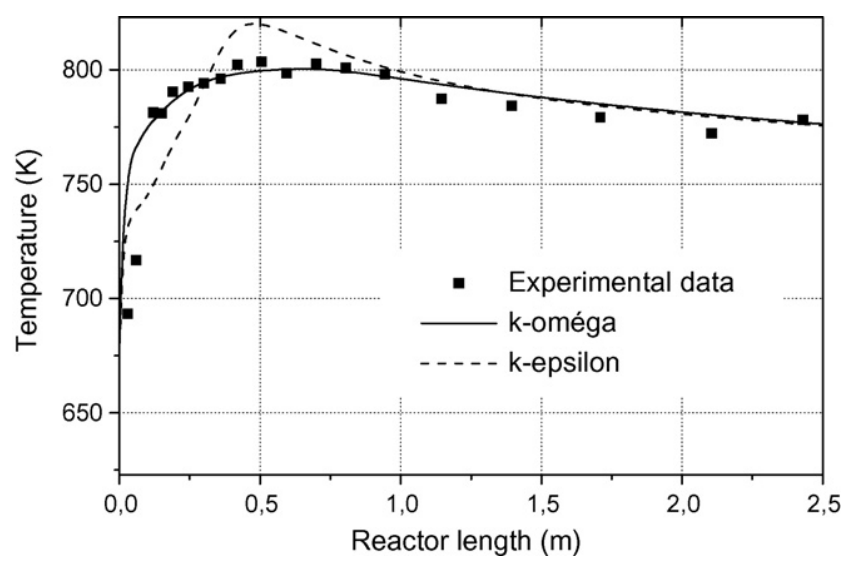

Fig. 4. Simulated wall temperature using a $k$-epsilon and a $k$-omega turbulent model for a reactive flow. reactor from inlet up to $1 \mathrm{~m}$. This zone is more difficult to model because of the large axial and radial temperature gradients.

In previous papers, Dutournié et al. [12], Oh et al. [13] used the $k-\varepsilon$ model to represent hydrodynamic for this kind of reactor. However, it was shown that the $k-\omega$ model is more suitable in our conditions to model the hydrodynamics combined with heat transfer and chemical reaction. This model represents more accurately the flow and especially the boundary layers. It will then be used in all calculations presented hereafter.

\subsection{Arrhenius rate based on the two step chemistry mechanism}

\subsubsection{Temperature profile}

To validate our model for a wider range of experimental conditions, calculations were performed with four different equivalence ratios. The experimental mass flow inlets are summed up in Table 3. The experimental data profiles for the four conditions are shown in Fig. 5. The mass flow inlet composition has been chosen for the experimentally significant difference observed on temperature profiles at wall. In all simulations, the operating conditions (inlet and sand bath temperature, gradient and heat transfer coefficient) are set to values shown in Table 2 .

The simulated and experimental wall temperature profiles are shown in Fig. 6. A good agreement between simulated and experimental temperatures is obtained for each boundary condition. For tests 2, 3 and 4, the spacing from the peak to the reactor entrance predicted by the simulation is smaller than the experimental one. Nevertheless, for the four tests, the simulated

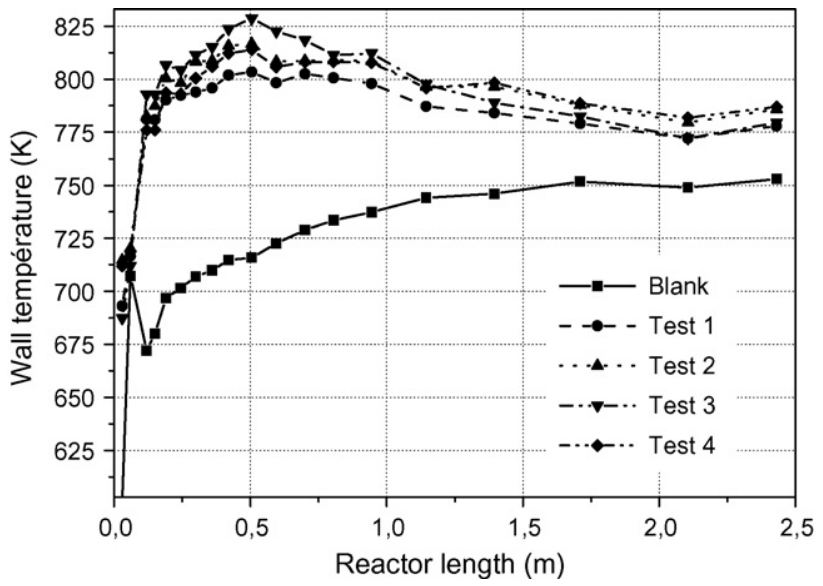

Fig. 5. Experimental temperature profiles. 

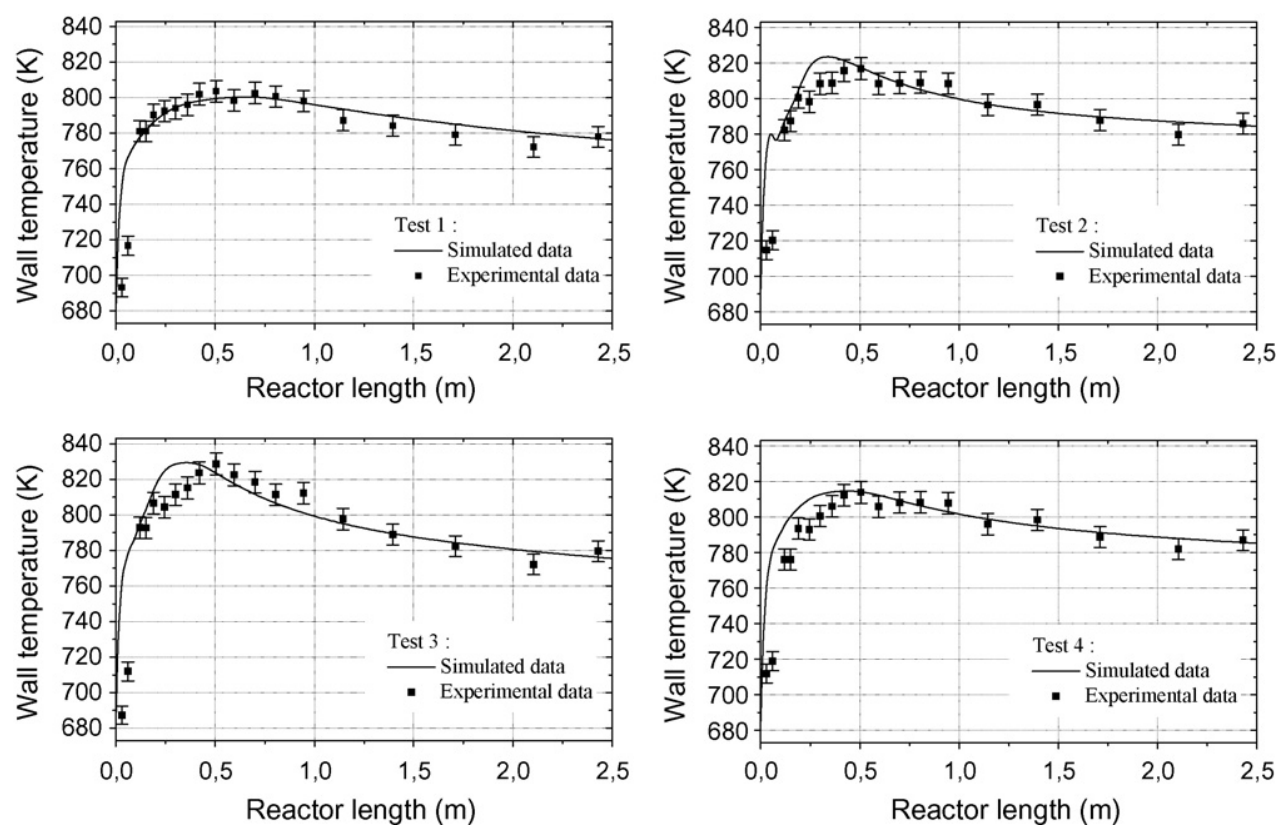

Fig. 6. Experimental data and simulated wall temperature profiles using an Arrhenius law for the four tested conditions.

height of temperature peak is in agreement with the experimental one. For these four tests, the maximum velocity value is close to $0.6 \mathrm{~m} / \mathrm{s}$. Knowing that the sound speed in supercritical water at $873 \mathrm{~K}$ and $30 \mathrm{MPa}$ is about $600 \mathrm{~m} / \mathrm{s}$, the Mach number in our case is far lower than 0.1. Regarding the result, the hypothesis of incompressible fluid seems to be a good approximation.

Moreover, a 2D axis-symmetric representation is required because of radial temperature gradient. The temperature field in the reactor for test 1 is shown in Fig. 7.

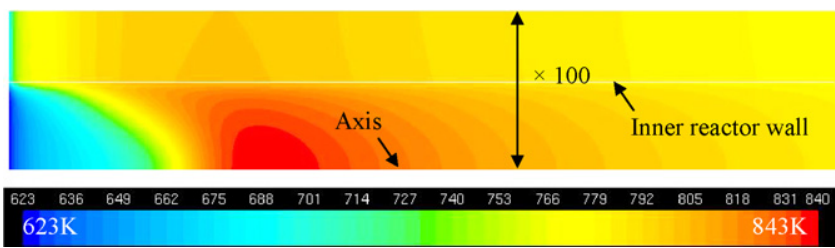

Fig. 7. Temperature (K) in the reactor during test 1.

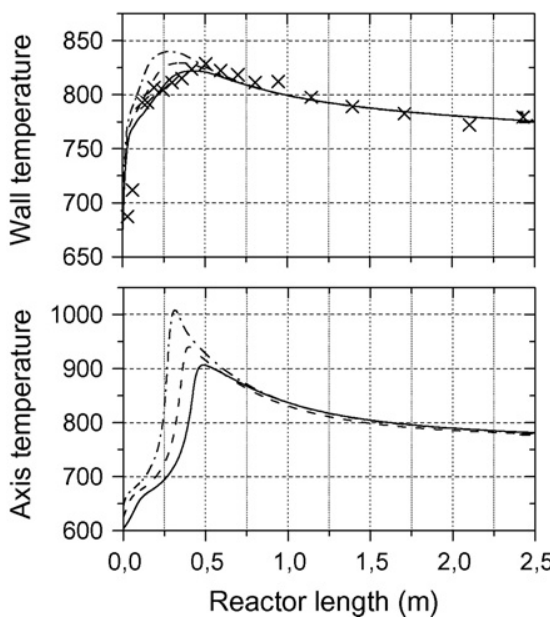

Two sources of error may lead to a shift of temperature peak:

- The inlet temperature which is assumed to be equal to $623 \mathrm{~K}$.

- The heat transfer coefficient between the reactor and the fluidized sand bath.

They are studied in the following paragraphs.

\subsubsection{Influence of inlet temperature on the oxidation process}

The inlet temperature does influence the temperature profile. The measure of temperature is not exact as the heater set temperature of $673 \mathrm{~K}$ is measured at the wall. Then flowing in the tube between the heater and the reactor, water is cooled. The inlet temperature is assumed to be about $623 \mathrm{~K}$. Two additional experimental tests at 603 and $643 \mathrm{~K}$ have been simulated for test 3 where the shift is maximum. The wall
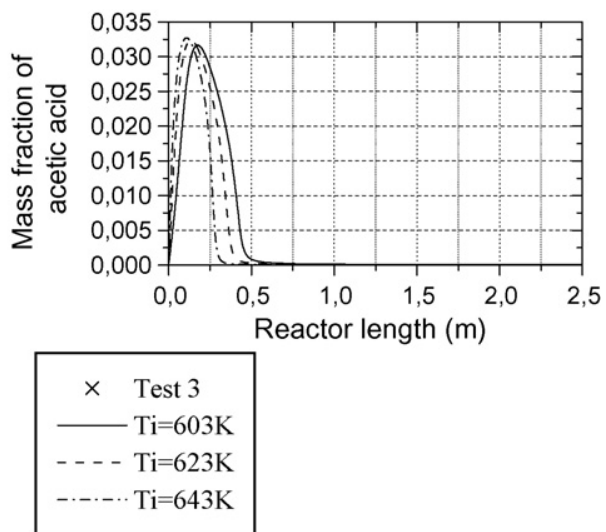

Fig. 8. Influence of inlet temperature on acetic acid mass fraction, axis and wall temperatures. 
temperature, the axis temperature and the acetic acid mass fraction for the three tested inlet temperatures are shown in Fig. 8.

The increase of inlet temperature leads to a faster reaction start-up. According to Fig. 8, the acetic acid oxidation with an inlet temperature of $643 \mathrm{~K}$ is slightly faster than for $603 \mathrm{~K}$. Thereby, the temperature peak is shifted toward the reactor inlet when the inlet temperature increases. Furthermore, the maximum temperature and the slope are higher than for $603 \mathrm{~K}$. So, the inlet temperature is able to control the shape of temperature profile and the axial temperature peak.

Roughly, $1 \mathrm{~m}$ after the reactor inlet the oxidation reaction is completed. From 1 to $2.50 \mathrm{~m}$, the wall temperature and the reactor temperature are absolutely linked to fluidized sand bath temperature.

The inlet temperature is a sensitive parameter which defines the locus of the reaction start. Using an inlet temperature of $603 \mathrm{~K}$, the shift between the experimental temperature peak and the simulated temperature peak decreases. However, the height of temperature peak decreases too.

\subsubsection{Heat transfer coefficient}

The estimated value of heat transfer coefficient between the external wall and the fluidized sand bath is in the range from 340 to $580 \mathrm{~W} / \mathrm{m}^{2} \mathrm{~K}$. The influence of this parameter must be assessed. Three numerical simulations were carried out using a heat transfer coefficient value of 400, 500 and $600 \mathrm{~W} / \mathrm{m}^{2} \mathrm{~K}$.

The results introduced in Fig. 9 show a little influence of the heat transfer coefficient on the oxidation process. It slightly influences only the wall temperature. To summarize, the heat transfer coefficient is not a sensitive parameter in this process inside the simulated range.
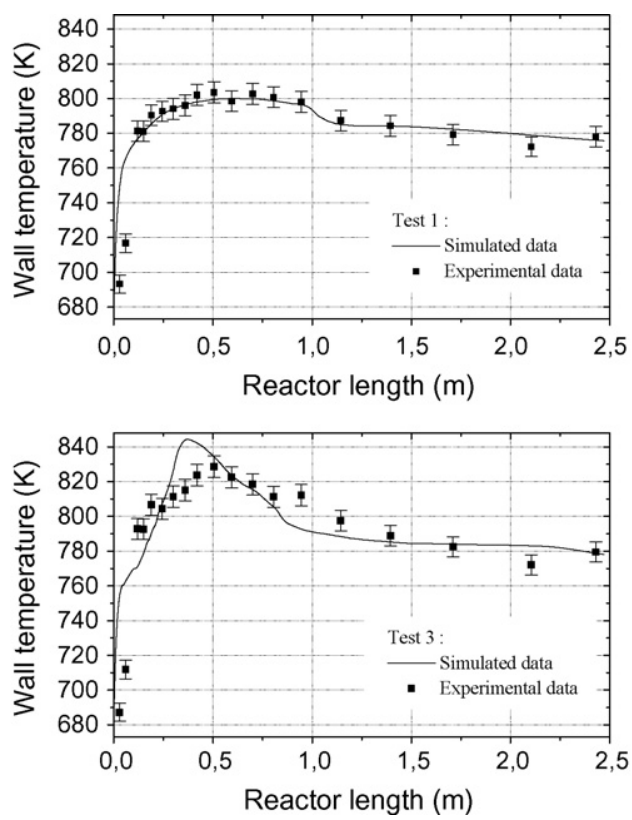

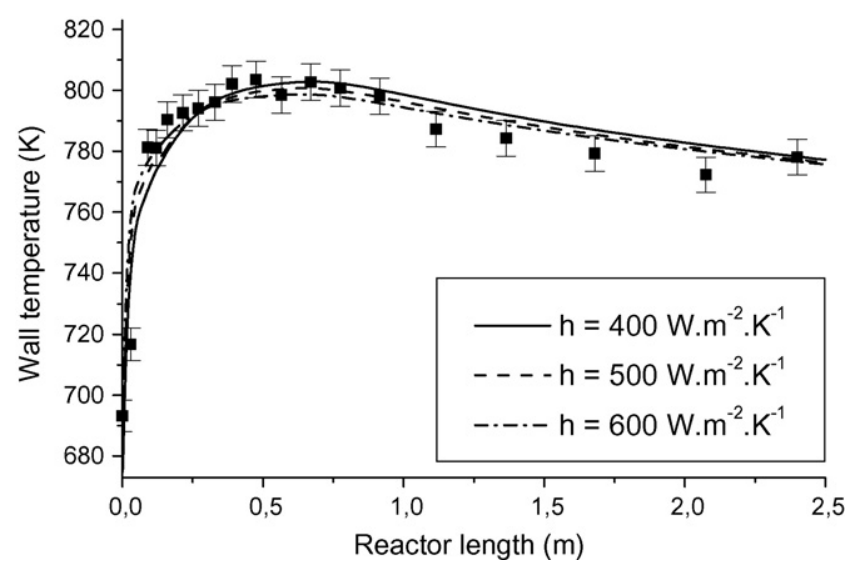

Fig. 9. Influence of heat transfer coefficient on wall temperatures.

\subsection{Mean reaction rate modelled using EDC model}

Using the same two-step reaction mechanism for dodecane oxidation, the mean reaction rate is computed using the EDC model. The simulations of test 1-4 are performed using the conditions described before. The inlet temperature is set to $623 \mathrm{~K}$. The simulated temperature profiles for the four tests are shown in Fig. 10.

The simulated temperature profiles for test 1,2 and 4 fit with the experimental data. On the contrary, the simulation of test 3 predicts a wall temperature profile with a different shape than the experimental one. However, in these four tests the simulated locus of temperature peak is in good agreement with experimental one. The EDC model is able to rightly predict the locus of reaction inside the reactor. The height of temperature peak is well predicted for test 1 and 2 , and is overpredicted for test 3 and 4, respectively, with +18 and $+10 \mathrm{~K}$.
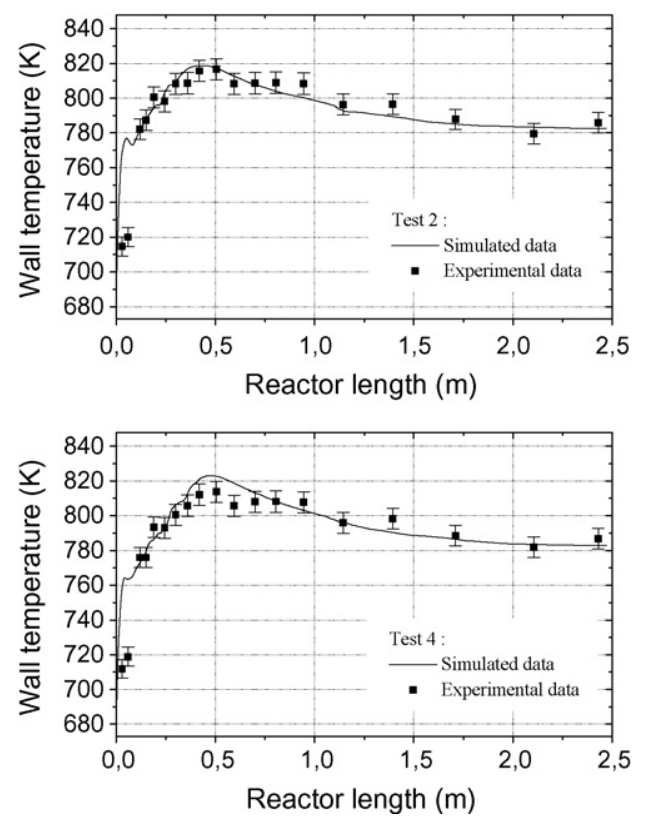

Fig. 10. Experimental data and simulated wall temperature profiles using an EDC model for the four tested conditions. 


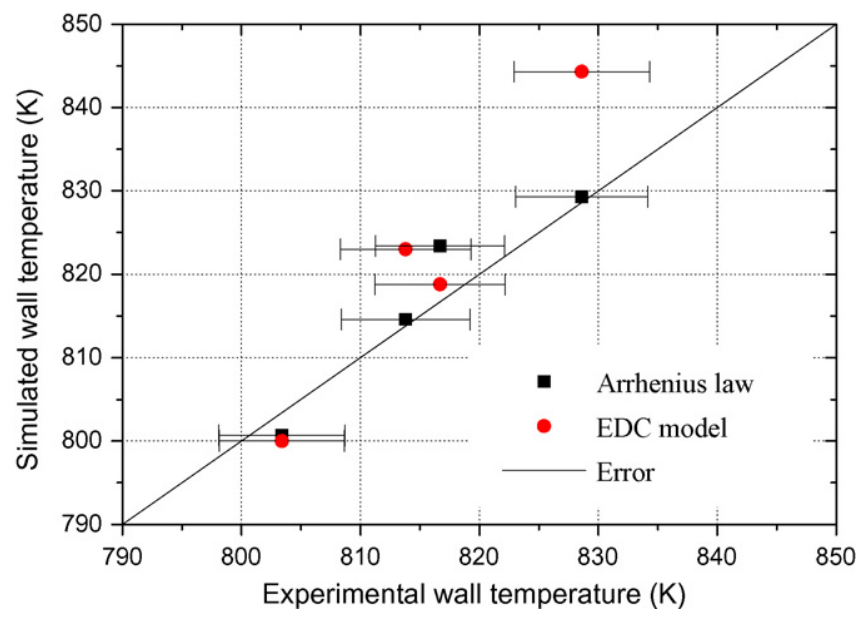

Fig. 11. Simulated heights of temperature peak against the experimental ones.

Nevertheless, except for test 3 , the simulated temperature profiles using EDC model are in good agreement with the experimental ones.

\subsection{Discussion}

Modelling the reaction rate using Arrhenius law or EDC model have been carried out. Both approaches give good results. To compare the effect on the turbulence on chemical reaction in the SCWO process, two criterions have been defined:

- The height of temperature peak which is linked to the local reaction rate inside the reactor.

- The distance between the temperature peak and the reactor inlet, which defines the ability of the model to predict the reaction rate. It can be influenced by the kinetics of chemical reaction or by the species transport in the eddy motion.

Fig. 11 shows the simulated height of temperature peaks plotted against the experimental ones. Thereby, except for the test 3 using an EDC model, the both approaches give similar results. Moreover, both approaches seem to overpredict the heights of temperature peak, especially when the temperature

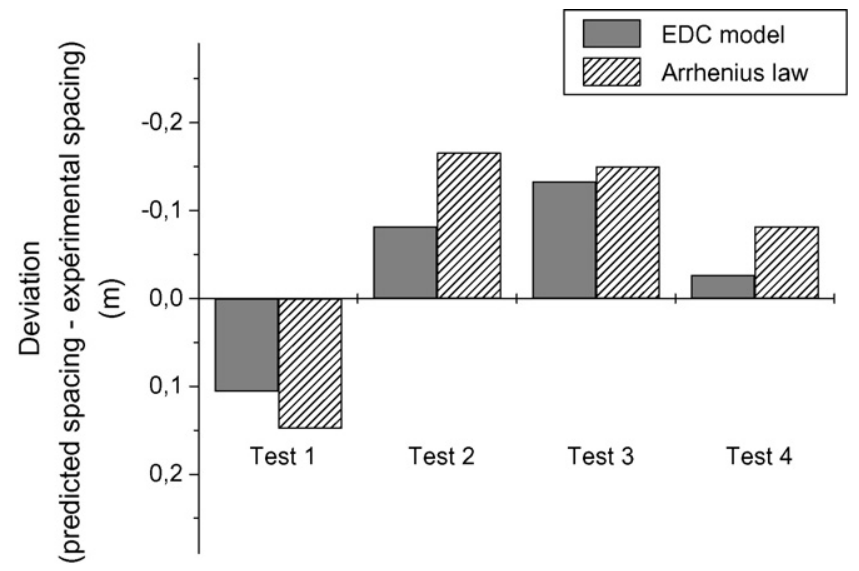

Fig. 12. Deviation between the simulated spacing using an EDC model or an Arrhenius law and the experimental ones. peak is important. Indeed, when the reaction is very local, the temperature gradient is higher and is more difficult to compute.

Fig. 12 shows the deviation between the simulated spacing using an EDC model or an Arrhenius law, and the experimental one. For all tests, the simulated location of the reaction is different from experimental one. However, data using the EDC model are more in agreement with experimental data using an Arrhenius law.

\section{Conclusion}

In this study, a CFD modelling of a tubular reactor has been carried out with a 2D axis-symmetric representation and a comparison with the experimental results has been achieved. The hydrodynamic model within the framework of the flow of a supercritical fluid and the influence of turbulence on reaction rate, have been investigated. The turbulent non-reactive flow is well-represented using the $k-\varepsilon$ turbulent model. Nevertheless, the $k-\omega$ model gives better results with the addition of chemical reaction term.

The simulated wall temperature profiles using an Arrhenius law are in good agreement with the experimental ones, though a shift of temperature peak toward the reactor entrance is observed.

The heat transfer coefficient between the reactor wall and the fluidized sand bath does not influence the oxidation reaction significantly. On the other hand, the inlet temperature is a sensitive parameter. The decrease of the fluid temperature at the reactor inlet leads to a shift of temperature peak which corresponds to a decrease of reaction rate. The height of temperature peak decreases as well as the inlet temperature decreases.

The use of an EDC model to compute the mean reaction rate makes possible a better prediction of wall temperature profiles for three tests and predicts more accurately the temperature peak locus and so the reaction rate. The reaction rate may be controlled by the molecular mixing and not by chemical kinetics in a supercritical water oxidation reactor.

A future application is the simulation of the counter flow double shell reactor where stirring and heat exchange between two counter-current fluids have to be considered.

\section{References}

[1] P. Kritzer, Corrosion in high-temperature and supercritical water and aqueous solutions: a review, J. Supercrit. Fluids 29 (2004) 1-29.

[2] M.M. Dipippo, K. Sako, J.W. Tester, Ternary phase equilibria for the sodium chloride-sodium sulfate-water system at 200 and 250 bar up to $400{ }^{\circ} \mathrm{C}$, Fluid Phase Equilibr. 157 (1999) 229-255.

[3] O.I. Martynova, Solubility of inorganics compounds in subcritical \& supercritical temperature, in: High temperature, High Pressure Electrochemistry in Aqueous Solutions, NACE-4, Houston, Texas, 1976.

[4] F.J. Armellini, J.W. Tester, Experimental methods for studying salt nucleation and growth from supercritical water, J. Supercrit. Fluids 4 (1991) 254-264.

[5] J. Abeln, et al., Supercritical water oxidation (SCWO): a process for the treatment of industrial waste effluents, High Pressure Res. 20 (2001) 537-547.

[6] M.J. Cocero, J.L. Martinez, Cool wall reactor for supercritical water oxidation-modelling and operation results, J. Supercrit. Fluids 31 (1) (2004) 41-55. 
[7] E. Fauvel, et al., A double-wall reactor for hydrothermal oxidation with supercritical water flow across the inner porous tube, J. Supercrit. Fluids 28 (1) (2003) 47-56.

[8] Y. Calzavara, et al., A new reactor concept for hydrothermal oxidation, J. Supercrit. Fluids 31 (2004) 195-206.

[9] E. Fauvel, et al., A new reactor for hydrothermal oxidation with an inner ceramic tube, in: Seventh Meeting on Supercritical Fluids, Antibes Juanles-Pins (France), 2000.

[10] P. Dutournié, J. Mercadier, Supercritical waste hydrothermal treatment modelisation of non-stationary phenomena in reactor, J. Supercrit. Fluids 32 (2004) 153-160.

[11] A. Ermakova, V.I. Anikeev, Modeling of the oxidation of organic compounds in supercritical water, Theor. Found. Chem. Eng. 38 (4) (2004) 333-340.

[12] P. Dutournié, J. Mercadier, P. Cezac, Simulation of a tubular reactor for supercritical water oxidation, in: Second European Congress of Chemical Engineering, Montpellier, France, 1999.

[13] C.H. Oh, R.J. Kochan, J.M. Beller, Numerical analysis and data comparison of a supercritical water oxidation reactor, AIChE J. 43 (6) (1997) $1627-1636$.
[14] N. Zhou, et al., A computational model for SCWO of organic toxic wastes, Adv. Environ. Res. 4 (2000) 79-95.

[15] W.P. Jones, B.E. Launder, The prediction of laminarization with a twoequation model of turbulence, Int. J. Heat Mass Transfer 15 (1972) 301-314.

[16] D.C. Wilcox, Dilatation-dissipation corrections for advanced turbulence models, AIAA J. 30 (11) (1992) 2639-2646.

[17] G. Limousin, Oxydation hydrothermale de déchets organiques contaminés, in: in Chimie Analytique et Environnement, Université de Bordeaux I, 2003.

[18] F.B. Magnussen, On the structure of turbulence and a generalized eddy dissipation concept for chemical reaction in turbulent flow, in: Presented in 19th American Institute of Aeronautics and Astronautics Aerospace Science Meeting, St. Louis, Missouri, USA, 1981.

[19] S.F. Rice et, R.R. Steeper, Oxidation rates of common organic compounds in supercritical water, J. Hazard. Mater. 59 (1998) 261268. 